\title{
De-foreignizing a Sound: Computer-assisted Pronunciation Practice in Learning a Foreign Language
}

\author{
Herbert Mushangwe \\ Hebei University, Baoding, 071002, China
}

\begin{abstract}
This paper examines the use of computer-assisted pronunciation practice in teaching Chinese as a foreign language. The paper is based on the concept of de-foreignizing sounds for a foreign language. Ten participants in 2012 and 40 participants in 2013 from the University of Zimbabwe participated in this study. Participants were recorded producing some Chinese sounds under strict guidance of the teacher, and then edited audios were given back to the participants for their own listening practice. The results showed that after the computer-assisted pronunciation practice, over $75 \%$ of the students had better perception of the Chinese second and third tones which they were not able to differentiate before the computer-assisted pronunciation practice. This paper concludes that; though this computer-assisted pronunciation practice might be time consuming, it can be also an effective method to stimulate students' interest in Chinese.
\end{abstract}

Index Terms - computer-assisted pronunciation practice, sound perception, foreign language environment, deforeignizing a sound

\section{INTRODUCTION}

This paper aims to explore the possibilities of using computer-assisted pronunciation practice in foreign language teaching in order to help students develop better perception of Chinese sounds. The paper is based on the concept of deforeignizing sounds from a foreign language. The term "de-foreignizing" or "deforeignization" is not a new term in linguistics; for instance Rajagopalan (2010) used this term to describe a situation whereby English language loses its 'foreign' status and develops a "distinctive local flavor and coloring". As a result, it becomes a local language like any other languages. In this paper the term deforeignization is defined as a process of making sounds for a foreign language appear to be more native or more familiar by using the learners themselves as the producers of near native sounds. The main argument is that when students listen to their own pronunciation the sounds they hear will be more familiar, thus more perceivable than when they listen to a foreigner pronouncing sounds for a foreign language. Since students learning a foreign language are normally in an environment where they rarely listen to native speakers in daily conversations it is therefore difficult to comprehend certain sounds for the target language, hence deforeignizing foreign sounds attempts to make the learner grasp the foreign sounds faster.

Listening and speaking Chinese is a fundamental challenge for students at the University of Zimbabwe, a situation which causes many students to give up learning Chinese language. Gilbert (1995) argues that "if learners cannot hear well, they are cut off from the language they are studying, and if they (learners) cannot be understood easily, they are also cut off from conversation with native speakers" (p. 1). Wong (1987) also agrees with this point thus he says that even when the non-native speakers' vocabulary and grammar are excellent, if their pronunciation falls below a certain threshold level; they are unable to communicate efficiently and effectively. This shows that there is the need for all foreign language learners to strive for good pronunciation. However, as Nooteboom (1983) noted, speech production is affected by speech perception, thus there is need to work on speech perception first for the learners to have better pronunciation as well as better listening abilities.

This paper aims to show the possibilities of using students' own pronunciation through sound editing software to help improve sound perception of Chinese's sound system, which in turn helps to create a base for better pronunciation. We believe that use of computer-assisted pronunciation practice which in this case helps to deforeignize the Chinese sounds, making sounds more native and easy to comprehend thus students' interest to learn Chinese language will be raised. Though this practice method was done based on the University of Zimbabwe's Chinese language teaching and learning experience; it is also expected to benefit other researchers, foreign language teachers and learners who are not necessarily researching, teaching or learning Chinese language.

\section{BACKGROUND AND LITERATURE REVIEW}

At the University of Zimbabwe the majority of Chinese language students do Chinese as a third subject for their Bachelor of Arts curriculum or as a foreign language course for Tourism and Hospitality Degree. There are however a few students from such departments as Psychology, Linguistics and Business Studies who opt for Chinese language as 
an optional course. All of these students normally speak their mother tongues or English both during Chinese class time and outside class time, this thus entails that these students are over-occupied with other core-courses, and the environment is not conducive for practicing both listening and speaking Chinese. This in turn affects students' language proficiency, such that even after studying Chinese language for a long time, they are not confident to speak. This problem is a chain problem that results from poor perception of Chinese sounds which in turn affects students' ability to imitate the foreign sounds which they learn.

The major challenge we were facing at the University of Zimbabwe during Chinese phonetic and lexical practice was that the teacher would engage students in repetitive practice which were proving to yield little results since the majority of students would forget what they practice and during review of previous lesson the majority of students would have forgotten what they practiced in the previous lesson. Since the weekly contact hours were limited to 6 hours only, the process was not only tiresome but also time consuming and discouraging for both the students and the teacher.

In our classroom phonetic practice the teacher would make the student or students imitate him until that given student or the majority of students are able to at least imitate the given sound or phrase correctly or just fairly correct. This practice method has the following indirect assumptions:

1. The student has already grasped the sound or given phrase;

2. The student will remember that given sound or phrase;

3. After class the student will be able to imitate the teacher without the teacher's guidance.

After class students would be expected to listen to audios and practice on their own, however the majority of students complained that the voices they were hearing from the Chinese language audios made by native speakers were too difficult to imitate and they would not hear anything except just a combination of sounds thus they would forget most of the sounds and phrases learnt in previous class practice. In other words as Badin, Bailly and Boë (1998) would put it; they were 'phonologically deaf'. As a result, poor perception of the Chinese sounds was negatively affecting students' pronunciation, hence there was need to improve students' sound perception for Chinese sound system. In 2012 this computer assisted practice was done as a way of stimulating students' interest in Chinese language and later in 2013 it was done mainly as remedial work to help students improve their pronunciation.

Listening and pronunciation seem to be common challenges that are faced by students learning a language outside the target language environment. There is much research relating to sound perception and pronunciation practice in second language learning such as Major (1987), Flege (1995) and Rochet (1995). Many of these researchers agree with the notion that language learners outside the target language environment normally experience listening challenges. For instance, Flege (1995) states that "foreign accents may make non-natives difficult to understand, especially in non-ideal listening conditions" (p. 234). It is also generally agreed that poor sound perception is the main cause for listening challenges. Tomatis argues that "before children speak a language they must be able to hear the particular sounds and auditory frequencies of that language" (Thompson, 1993, p152). This therefore suggests that the base for good pronunciation is good perception of the target language's sounds. There are many suggestions from different researchers on how to attain good pronunciation; for instance, Ashby (2012) recommends that at tertiary level a short introduction course in articulatory phonetics course could be helpful for foreign language learners. Field (1995) proposes dictation as one of the ways of promoting lexical perception.

However, in order to improve language learners' sound perception and pronunciation practice especially outside the target language environment there have been so much technological developments across the world. Computer-assisted language learning popularly known as (CALL) is one example of such developments. Levy (1997), defines CALL as an "attempt to apply computer technology in language teaching" (p. 1). Some scholars call it Technology-enhanced language learning. Nazlı (2005) observes that in CALL the learner is first presented with a rule and some examples, and then answers a series of questions which test his/her knowledge of the rule and the computer gives appropriate feedback and awards a mark, which may be stored for later inspection by the teacher. Many scholars believe that CALL method can strengthen learning motivation and provide immediate feedback that encourages subsequent learning (Heift \& Rimrott, 2008; Hmard, 2006). The method can be used to reinforce what the student has already learnt in the classroom or as a remedial tool to help learners who require additional support. Some of these CALL manifestations include virtual learning environment and Web-based distance learning.

One such development includes the Virtual Talking Head and Speech Mapping proposed by Badin, Bailly, and Boë (1998). In this method the teacher uses audio-visual speech stimuli in order to evaluate and improve the learner's perception of the target language's sounds as well as helping the learner produce the corresponding articulations by acquiring the internalization of the relations between articulatory gestures and resulting sounds. All such methods, however, require skilled and expensive technological support that might not be afforded in developing countries such as Zimbabwe.

Most developed countries are now developing language learning software programs to help language acquisition mostly outside the target language environment. For example, there are so many foreign languages' learning software programs such as; the Rosetta Stone software, the 101 Languages of the World software, the Instant Immersion 33 Languages software, and many others. Such software programs follow the notion that "in second language teaching many teachers test listening rather than teaching it" (Sheerin, 1987). The modern language learning software programs allow the learner to practice their pronunciation by giving the learner an option to record him or herself, and a computer 
compares the learner's pronunciation to that of the native speaker after which the computer gives a score for resemblance level. For example, when using Instant Immersion 33 Languages software, one needs a computer or just a CD player, a sound card and a microphone for the practice. This learning software is more like a game where you play and win or lose. For pronunciation practice the speaker plays a word and immediately repeats it into the microphone, then play back the sequence and can hear the speaker's pronunciation compared to the native speaker. Former president of Alamo PC, in a review of the Instant Immersion 33 Languages software, mentioned that at the end of practice session she felt quite confident with several words and phrases. Also she felt the process was quite funny since the program is totally aural and does not require reading (Ives, 2004).

While all such software programs might be effective in language learning in many countries, the situation is completely different in Africa especially in Zimbabwe. Though at the present many people are now using computers and have access to internet in Zimbabwe, it should be noted that the motivation to learn foreign languages is low and cannot be compared to that of students in developed countries. Also students do not buy these software programs due to economic hardships, lack of interest, lack of information about such software programs, lack of technological knowhow, and many other reasons.

Apart from the above, there are also other pronunciation learning methods such as shadowing; this is a language learning technique through which an audio in the language that one is learning is used as the bases, while listening to the audio, one attempts to repeat immediately after hearing it (Nagel, 2011). This method might be effective if the student is able to discern the sounds he or she hears from the audio, so for the University of Zimbabwe students it could have been ineffective since the students were having problems in imitating what they hear from the audio.

In this paper we argue that perception for "foreign" sounds is difficult to perceive because sounds are produced by a foreign person, however if the same sounds for the target language are produced by the learner himself then the pronunciation will become localized. Wagner (2012) argued that perception of unfamiliar foreign language sounds without first language equivalent is troublesome. This therefore implies that in second language learning sound perception of the first language forms the base of acquisition of the target language. Wagner (2012) further explained that; "once perception of foreign speech sounds is accurately established, this perception provides a foundation for accurate production" (p. 12). It is also believed that when one has learnt a first language, other speech sounds are typically perceived in terms of the phoneme categories of the native language (Van, Broerse and Pacilly, 2011).

In this research it is therefore hypothesized that it is possible to improve learners' sound perception for a foreign language by deforeignizing foreign sounds. Deforeignizing a sound as already noted implies "nativizing" a sound that does not belong to first languages, in other words it is a way of making those sounds of a foreign language be perceived through the native language's sound system. This is achieved by recording the learner under strict guidance of the teacher, after which among the learner's recorded sounds a closer to standard pronunciation sound will be selected. After computer editing, the learner will then listen to his or her own pronunciation which is native to him or her in the sense that the sound is not produced by a foreigner; this will then form the base of acquiring a foreign sound.

The assumption is that by comparing his/her own pronunciation to that of the native speaker, the learner will be able to attain better perception and pronunciation of the foreign sound. The sound will become native to the learner because at the end he or she will be listening to his or her own pronunciation. In this paper we therefore seek to answer the following questions:

1. Does computer-assisted pronunciation practice make Chinese tones familiar to the learner?

2. Does computer-assisted pronunciation practice improve students' perception of Chinese tones?

3. Does computer-assisted pronunciation practice help retain the practiced tones?

\section{Methodology}

This computer-assisted pronunciation practice was administered initially to 10 University of Zimbabwe part one Chinese language students; the students were having pronunciation difficulties and they would easily forget what they learn. The first trial of computer-assisted pronunciation practice was for Chinese lexical and semantic pronunciation practice, where participants were given short written dialogues which they had to memorize or just familiarize with over a period of 2 days. The dialogues were written in both characters and pinyin because almost all the students could not read Chinese characters by the time of recording. On the day of recording each word or phrase was then read under the guidance of the teacher. During recording the teacher would read the sound or phrase while the student imitate.

The recorded sounds were edited to make continuous audios which were then given back to the participants as part of their sound practice. The impact of this computer-assisted pronunciation practice was then evaluated by both teachers and students through discussions and questionnaires. Discussions with other Chinese language teachers were quite helpful in terms of providing ideas on how to improve this approach of computer-assisted pronunciation practice. Apart from discussions, questionnaires were also used to gather information about the students' experience and feelings during the practice and after listening to their own pronunciation. Recorded audios were also played to other students who were not part of the computer-assisted pronunciation practice and questionnaire method was used to gather their comments and opinions on this Chinese learning approach. This was helpful in evaluating the possible impact of this computer-assisted pronunciation practice on both the participants and non-participants.

\section{Participants}


Fifty students aged between 19 and 28 years from the Confucius Institute at the University of Zimbabwe participated in both the first and second computer-assisted pronunciation practice. All the participants had studied Chinese for a period of about 6 months when the recordings where done, participants' Chinese proficiency level was still for early beginners. In 2012, 10 out of 41 students from the 2011 Bachelor of Arts level 1 class were randomly selected to participate in the computer-assisted pronunciation practice. In 2013, 40 out of 64 Bachelor of Arts level 1 students who were having problems in differentiating Chinese second tone and third tone were selected to take part in the computerassisted pronunciation practice.

\section{Procedures}

Since the first practice could not be evaluated quantitatively to find out the actual impact of the practice on students' pronunciation, in 2013 a follow up computer-assisted pronunciation practice was carried out, 64 students were initially recorded producing the Chinese 4 tones using the syllable $/ \mathrm{ma} /$ and all the audios were analyzed using praat software. Forty out of the 64 students who were having problems in differentiating between second and third tones were invited to take part in the computer-assisted pronunciation practice.

All the recordings were done in the Confucius Institute's language lab where there was minimum noise. An Intel Core 3 Toshiba Satellite laptop and a new microphone were used for recording. AVS screen capture was used for all voice recordings. During the recording, students would imitate the teacher's pronunciation while reading the same sound or phrase written on the paper (see appendix). A given tone, consonant, word or phrase would be repeated for several times until the student manages to produce the sound or phrase correctly or at least perceived by the teacher as fairly good. As many sounds as possible would be recorded until the teacher feels that the student has managed to imitate the sound or phrase either correctly or just fairly well. This was following the same practice method in the classroom but this time everything would be recorded in order to capture that moment when the student manages to produce the sound or phrase correctly.

After recording all audio files were imported to AVS Video editor and would be then dragged to the sound editing column, where each audio file could be cut, separated and or mixed. This was an important stage because if wrong sounds were mixed this could have given the listeners an inappropriate point of reference during participants' pronunciation practice. After cutting, the inappropriate parts and wrongly produced sounds were deleted; the proper or fairly well produced sounds were then rearranged to make continuous audios.

For the Chinese lexical computer-aided practice the edited phrases were alternating with those of other students producing continuous dialogue, despite the fact that during recording of these phrases were done separately. The edited audios were produced as videos in AVI video format, however they were later converted into mp3 formats playable on cell phones and other media players so that participants could play them on their different mp 3 media players. The entire pronunciation practice was done within a day for all the 40 students and the editing was done over night, after which edited audios were given back to individual participants, students were encouraged to listen to their own audios and imitate their own pronunciation as much as they could. Five days after the computer-assisted pronunciation practice the 40 students were recorded again producing the same 4 Chinese tones. Audios recorded before and after the computer-assisted pronunciation practice were then compared.

\section{Acoustic analysis}

For the 2013 computer-assisted pronunciation practice, we used Praat software to analyze the students' pronunciation of Chinese tones before and after the computer-assisted pronunciation practice. This acoustic analysis was done in order to establish students' tone perception before and after the computer-assisted pronunciation practice. The analysis followed simple procedures where wave audios would be imported to the Praat software page and annotated to text grid, thus producing a text grid file. Then by simultaneously selecting the original sound as well as the textgrid file and clicking the edit option a textgrid in picture form would then pop up showing tone forms represented by lines above the labeled areas. Results for pre and post computer-assisted pronunciation practice were then compared to see if there were any changes in students' tone pronunciation after the computer-assisted pronunciation practice. Results of the acoustic analysis are shown in the following section.

\section{RESULTS AND ANALYSIS}

Feedback from the 2012 and 2013 computer-assisted pronunciation practice was extracted in different ways; the evaluation of the 2012 computer-assisted pronunciation practice was more qualitative while that of 2013 was more quantitative. In 2012 after participants listened to their own audios, a questionnaire was used to extract feedback from both participants and non-participants. Responses to the questionnaire showed that after the computer assisted pronunciation all the 10 participants were excited to hear themselves speaking fluent Chinese and they mentioned that it was now easier to imitate the phrases they pronounce on their own than imitating those that are produced by native speakers of Chinese, thus they expressed eager to use the same method in their future pronunciation practice.

Apart from participants' personal feedback, it was observed that students would keep on playing the audios either on their cell phones or computers. Also it was observed that some participants were even playing these audios to their friends and or family members. Whether the participants were showing off or not it is assumed that by repeatedly playing the audios this was a sign of motivation to learn Chinese, thus there was potential for the students to improve their listening and pronunciation skills. 
The computer-assisted pronunciation practice proved that the recording process is a method of pronunciation practice in itself, because as participants were following teacher's pronunciation repeatedly in a way they were practicing both pronunciation and listening. As observed from this pronunciation practice method after recording some participants would spontaneously say out sounds, words or phrases they produced during the recording. This shows that the recording process leaves a profound impact on the participants' thoughts, feelings and attitudes towards the target language. It was also observed that in a class where about 20 students dropped out Chinese, all the 10 participants of the 2012 computer-assisted pronunciation practice continued to take Chinese language in their second year. However, this might be possibly regarded as coincidental.

Apart from the above, the 2012 computer-assisted pronunciation practice also proved that students could imitate themselves better than they could imitate either the teacher or the voices of native speakers they hear from the Chinese audios. This was shown by the fact that the students could no longer forget their pronunciation as they used to do in class. All the ten participants of the 2012 exercise mentioned in the questionnaire that they could no longer forget the phrases they learnt also during class exercise; the participants were still able to use some of those phrases from the computer-aided practice. Thus this shows that if the recorded sounds are well edited leaving those sections that the student produced well then, it will be easy for the student to imitate his or her own pronunciation and achieve better pronunciation.

The 2013 follow up computer-assisted pronunciation practice which was done for those students who had problems in differentiating the Chinese language's second and third tone shows that after the computer-assisted pronunciation practice 31 students out of 40 had significantly improved as would be shown in the praat pictures in the following section. Students were recorded before and after the computer-assisted pronunciation practice and audios were analyzed using praat software. Students who could not differentiate between the second and third Chinese tones could now able to differentiate between these tones. This implies that after the pronunciation practice participants' perception for Chinese tones had improved. In this case we measure perception by the students' ability to different two sounds which he or she could not differentiate before the pronunciation practice. Below are samples from four participants chosen as representatives of the 40 samples which show the praat textgrid pictures for Chinese second tone and third tone forms before and after the computer-assisted pronunciation practice. Since all the praat pictures had almost a similar improvement as the ones below not all pictures could be used for the purpose of data presentation in this paper;

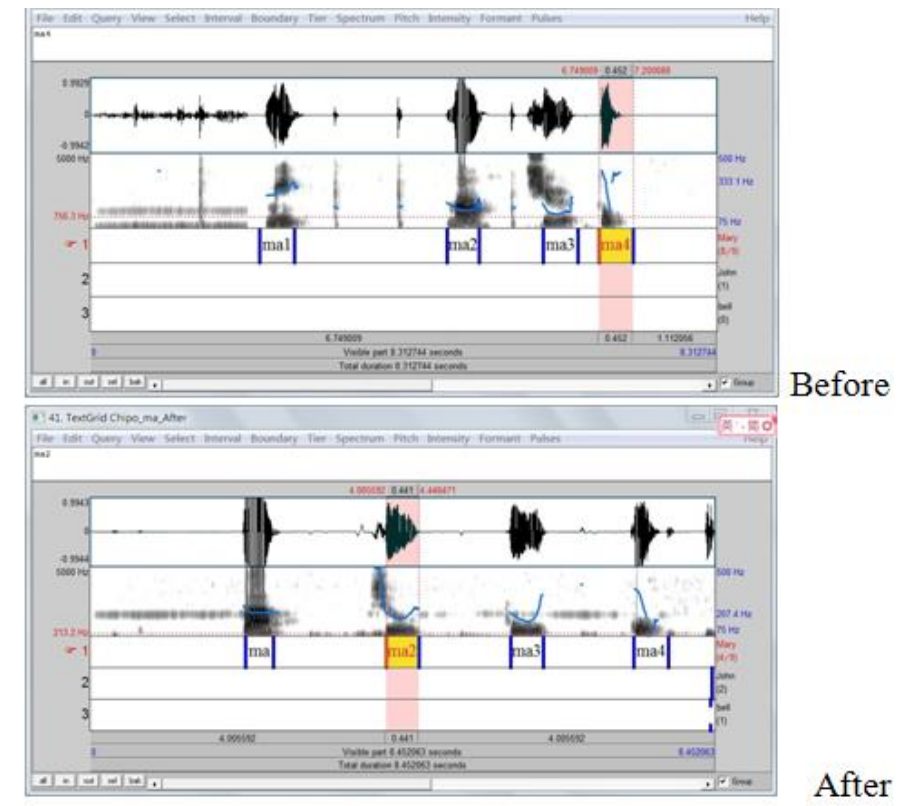

Figure 1: Student A, second and third tone before and after the practice

This textgrid picture for the student A shows that the student was producing Chinese second and third tone both as a low slightly curving tone. In these pictures /ma2/ represents second tone while /ma3/ represents third tone; both tones were produced with the sound [ma]. The /ma1/ and /ma4/ which are not part of this analysis represent first tone and fourth tone respectively. In the textgrid picture above it can be seen that the lines above the slot $/ \mathrm{ma} 2 / \mathrm{and} / \mathrm{ma} 3 / \mathrm{almost}$ look the same. The Chinese second tone is a rising tone while the third tone is a curving tone also known as fallingrising tone (Olle Linge, 2011; Liu \& Samuel, 2004). For the audios which were recorded before the computer-assisted pronunciation practice these students could not discern the difference between these two tones as can be seen above and in other textgrid pictures below. After the computer-assisted pronunciation practice the student was recorded again and the new tone form shows that the student could now distinguish /ma2/ and /ma3/ as can be seen from the above textgrid picture labeled "after". The line above /ma3/ has a more pronounced curving shape different from that of $/ \mathrm{ma} 2 /$, showing that this time the student had better perception of these two tones. The same results were also observed for 
student B below;

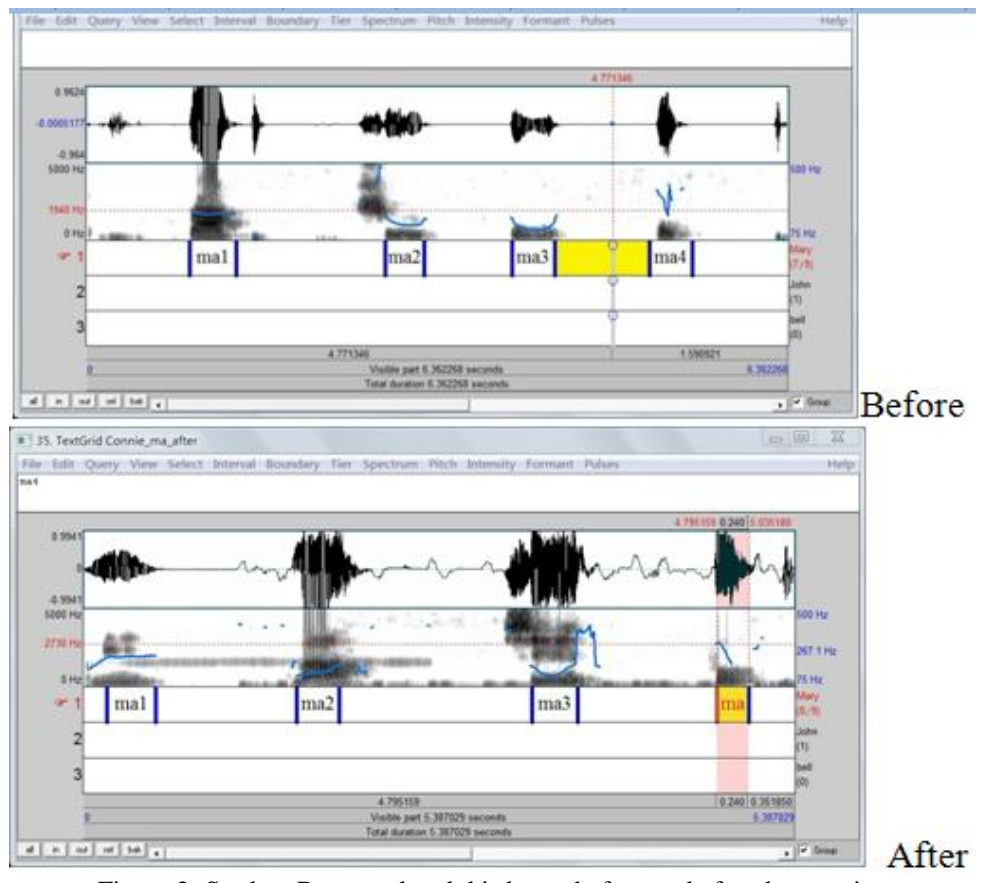

Figure 2: Student B, second and third tone before and after the practice

Before the computer-assisted pronunciation practice student B just like the student A was producing /ma2/ tone almost like /ma3/ tone both as low and slightly curving tones, but after the practice as can be observed from the textgrid picture labelled "after" the student's /ma2/ was now a clear rising tone without any curving shape as before, the student's /ma3/ could now be differentiated from /ma2/. In figure 3 below just like in the previous cases of student A and $\mathrm{B}$, before the practice student $\mathrm{C}$ produced the $/ \mathrm{ma} 2 /$ and $/ \mathrm{ma} 3 /$ tones as long low level tones with a slight rise at the end.

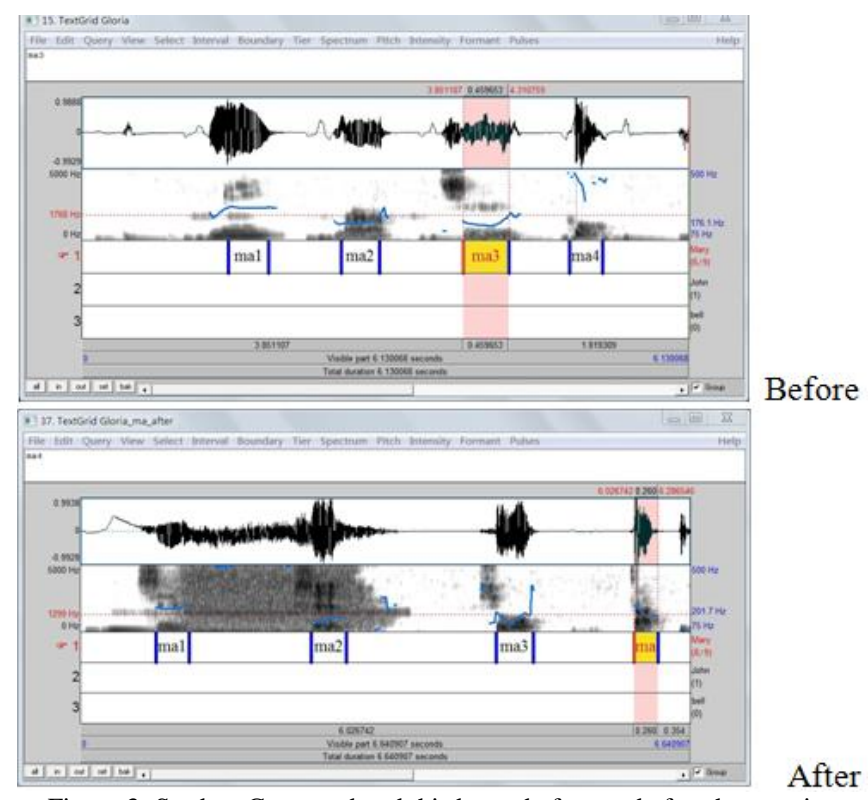

Figure 3: Student C, second and third tone before and after the practice

However, after the computer-assisted pronunciation practice the student C's /ma2/ tone was now a slightly rising tone which can be seen represented by the line above the slot labeled /ma2/, rising just below the dotted line. Above the /ma3/ slot the tone form shows a small curving line below the dotted line as shown on the picture labeled "after". Though the above student C's textgrid picture shows that the student's pronunciation of the Chinese second and third tone was not yet as perfect as it is supposed to be, but it should be noted that unlike before the practice there was now remarkable difference in this student's production of rising and curving tone. The last sample below also shows the same changes as in the above cases. 


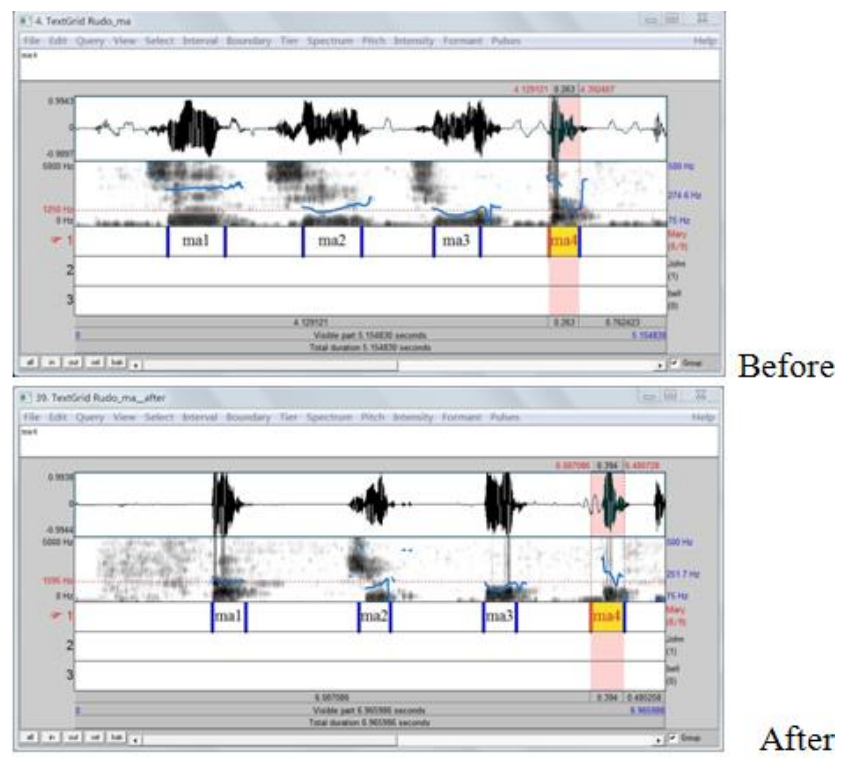

Figure 4: Student D, second and third tone before and after the practice

Before the practice student $\mathrm{D}$ also could not differentiate between the second and third tone, as can be seen from the above textgrid the /ma2/ tone and the /ma3/ tone were looking alike, with a slight curve at the beginning and a long slightly rising end. After the practice it was completely different. On the picture above it is shown that /ma2/ unlike before the practice, was now rising slightly from below the dotted line, while /ma3/ was falling from the dotted line to some point and then rising up again, producing a clear curving tone. This suggests that after the computer-assisted pronunciation practice Student $\mathrm{D}$ could now differentiate between second tone and third tone. Though this might not be the perfect Chinese third tone, it should be also noted that in all the samples for these four students before the computerassisted pronunciation practice the students could not differentiate the second and third tone, but after this practice all of them were producing these two tones differently.

Based on the results measured by praat software for all the 40 students it can be concluded that the 2013 computerassisted pronunciation practice is a potential teaching and learning tool. Both the recording process and the product of computer editing contribute to the sound practice, thus producing a unique pronunciation practice. In other words, the whole practice method shows that it is possible to solve sound perception problems by making students listen to their own pronunciation for a given sound. Thirty-one out of 40 participants of this pronunciation practice could differentiate the tones which they could not different before the practice, in other words about 77 percent of the participants positively benefited from this computer-assisted pronunciation practice.

\section{DisCUSSIONS AND RECOMMENDATIONS}

The first computer-assisted pronunciation practice which was done in 2012 was more general and was done as a remedial work to raise students' interest in Chinese. The evaluation did not show any measureable results for actual improvement in pronunciation but as already mentioned all the 10 students could imitate themselves better than they could imitate the native speakers. In other words students could discern their own pronunciation. Though it was concluded that students seem to find it easy to discern the pronunciation for the phrases they produce on their own, the results for this first computer-assisted pronunciation practice were too qualitative, such that we could not establish whether the practice had direct impact on student's pronunciation or not. It can be concluded that; the initial practice was more of raising interest in Chinese rather than pronunciation oriented; this is one major weakness of the first computer-assisted pronunciation practice. Despite this major weakness it should be noted that, students were motivated mainly by the fact that the Chinese sounds were no longer sounding "foreign" rather they were now more native to the participants, thus there was hope that they (students) would one day grasp this language.

While $100 \%$ of the questionnaire respondents for the 2012 practice showed that this method is a possible effective method for pronunciation practice, some Chinese language teachers argued that the method was likely to promote pronunciation errors which are directly caused by the students' mother tongue. The worry raised was that using learners' own personal pronunciation as the base of pronunciation practice promotes mother language negative transfer. However, considering that the pronunciation problems which were being experienced were mainly due to lack of motivation, the majority of teachers argued that this method was a crucial part of Chinese pronunciation practice outside the target language environment because it stimulates interest in the target language.

The praat results for the second computer-assisted pronunciation practice shows that after the practice students were now able to differentiate between the second and third tone which they could not differentiate before. Therefore, it can be argued that this computer-assisted pronunciation practice does have the potential to improve students' perception of the sounds for a given target language. The results suggest that editing of students' sounds and retaining the correct or 
partly correct sounds helped to show the students' potential. All the participants had potential to speak Chinese well but they possibly did not know that until we captured the moments they could imitate the teacher well. Therefore, when students listen to their own pronunciation from the audio they find it easy to imitate because it is something they once achieved.

In this paper we attribute the $77 \%$ improvement which was achieved after the computer-assisted pronunciation practice to the process of deforeignizing the Chinese tones. We argue that through the computer-assisted pronunciation practice the pronunciation of Chinese tones were deforeignized, thus making it easy for the students to imitate and differentiate between second and third tone which they could not different before the practice. There might be possibilities that the continuous imitation of the teacher helped the students to grasp the differences between second and third tone, however during class time students would always imitate the teacher but they would easily forget the proper pronunciation.

While some critics may argue that deforeignizing a sound promotes pronunciation which has a kind of "foreign accent", in this paper we reiterate that the most important thing in second language learning is for the learner to be able to communicate with natives without any misunderstanding. Elliott (1994) points out that; researchers are divided as to whether second language learners should acquire native pronunciation or just a near native pronunciation. In other words while native pronunciation is the main target in second language learning however the possibilities to achieve it perfectly is something that is still subject of discussion. Lund (2003) also states that; "only a tiny percentage of those who begin to learn a language as an adult achieve a pronunciation without an accent" (p. 10). For adult learners it is quite difficult to achieve native pronunciation, thus the majority of second language learners normally achieve near native pronunciation rather than accurate native pronunciation. Kadenge (2009) mentions that there is a distinct variation of English in Zimbabwe which is a sub-branch of African Englishes and this is as a result of 'indigenization of English sounds'.

This process where sounds of a foreign language are indigenized means that the process is natural. Therefore, deforeignizing a sound is just but an artificial method where foreign sounds are intentionally 'indigenized' so that they become easier to perceive for the learner. The main argument in this paper is that use of technology helps to determine the 'indigenization of foreign sounds' while learners are still beginners. In foreign language teaching teachers normally spend a lot of time trying to make learners achieve native pronunciation while at the end what is achieved is still a kind of pronunciation with foreign accent. Therefore, computer-assisted pronunciation practice helps learners to practice their pronunciation based on something that is achievable. The role of technology in this case is to combine those sounds which are well produced thus by cutting and joining these sounds which were once achieved gives students hope and preserves their own standard pronunciation for future reference.

The concept of deforeignizing a sound through computer-assisted practice gives assurance that students can speak Chinese better than they are currently doing; it predicts level of perfection that one can achieve before the student achieves that level. In other words, it gives students hope that they will be able to achieve the same fluency they achieved in the audio. Unlike in the classroom activities where students do not have a record of their potential, this computer assisted practice keeps student's 'best moments' thus it keeps on reminding them (students) that they can achieve better pronunciation.

The fact that students' correct pronunciation is retained such that student can refer back to the correct pronunciation if he or she forgets is an interesting part of the process of deforeignizing a sound. In classroom activities we do not keep the correct pronunciation for the students' future reference thus some students tend to forget what they would have practiced. During class when students' imitation of the teachers is good teachers will obviously use such words as 'good', 'excellent', 'well tried' etcetera, all such comments are motivational. Semke (1984) thus says that "supportive comments have a positive effect on students' motivation" (p. 201). In this deforeignizing a sound practice method the preserved sounds are not only evidence of students' achievement but also an act of appraising students' performance, since the editor will remove all wrongly produced sounds. Therefore, we recommend that since this pronunciation practice method is motivational, it is worth trying in teaching second language. We also recommend that for those students who might be having serious pronunciation problems for words and phrases this can be a good remedial activity.

\section{CONCLUSION}

In this paper we attempted to answer three major questions which were raised earlier on in this paper. Firstly, we wanted to know if computer-assisted pronunciation practice would make sounds for foreign language familiar to the learner. Secondly, we wanted to find out if this method was going to help students to improve their perception of Chinese sounds. Lastly, but not least we wanted to know if computer-assisted pronunciation practice would help students not forget what they practice. To a larger extent all these questions were answered.

The research shows that allowing language learners an opportunity to listen to their own voices while producing sounds for the target language is a helpful technique in learning a foreign language because it makes the sounds for the target language perceived as native or familiar to the learner, thus helping the learners to have a better perception of target language's new sounds. Students can also compare their own pronunciation with that of native speakers and through self-evaluation they can slowly be able to imitate near native speaker pronunciation. Also, this computer- 
assisted pronunciation practice can be a way of motivating language learners outside the target language environment, by capturing students' correct pronunciation, students are even able to forecast the level of fluency they can achieve, thus giving them hope in learning the target language. The recording process is also a way of preserving student's correct pronunciation, thus when the student forgets how to pronounce certain sounds he or she can still refer back to the audio and imitate his or her own pronunciation. It will be awkward if one cannot discern what he or she himself or herself is saying, hence in other words; self produced sounds are easier to perceive than sounds produced by somebody else let alone a foreigner. This process is what was termed deforeignizing a sound in this paper, making sounds for foreign language perceived as they are produced by the learners themselves.

Apart from the above, this computer-assisted pronunciation practice is also affordable; the researcher suggests that language learners can use this practice method with even cheap and locally accessible resources. Instead of using expensive computers and editing software, a simple phone with a recorder can be used for recording and then compare the pronunciation of the recorded sounds with that of the native speakers. The objective is for the learner to feel the difference between his or her own pronunciation with that of the native speaker.

One major weakness of this research is that, the practice was done at one institution only and it was done to help Chinese language students only, thus the questions that remain unanswered are; will this method produce similar results if it is used in teaching other languages other than Chinese and will the results be positive if it is used in other institutions? Apart from that we could not implement two or more different methods to measure the extent to which this method is effective. The question that might be asked is that; is this method the best method for teaching a foreign language? It is our hope that researchers and critics will continue to experiment with similar teaching methods and raise constructive criticisms in order to improve the teaching and learning of languages outside the target environment. From the results of the first pronunciation practice in 2012 and the second pronunciation practice in 2013 it was shown that this computer-assisted pronunciation practice is a worth trying method since positive results were obtained. The role of technology in language teaching and learning is ever growing and cannot be undermined, therefore, this method can be adopted as a foreign language learning and teaching technique. It is our hope that more extensive similar research projects will be carried out so as to develop cheaper and motivational computer-assisted teaching methods.

\section{APPENDIX 1. RECORDINGS}

\begin{tabular}{|c|c|}
\hline \multicolumn{2}{|l|}{ Recorded Chinese Tone practice (2013 practice) } \\
\hline \multicolumn{2}{|l|}{ Tones } \\
\hline \multicolumn{2}{|l|}{$\begin{array}{lccc}\text { First tone } & \text { mā } & \text { Second tone má } \\
\text { Third tone } & \text { mă } & \text { Fourth Tone } & \text { mà }\end{array}$} \\
\hline \multicolumn{2}{|l|}{ Recorded dialogue } \\
\hline 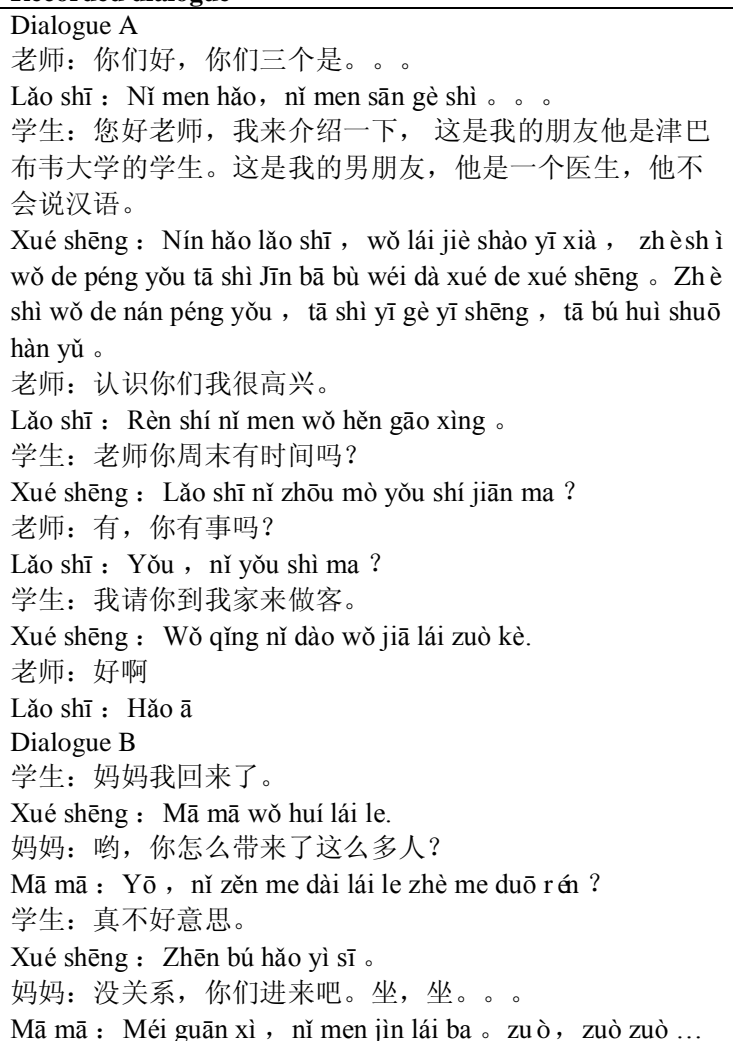 & 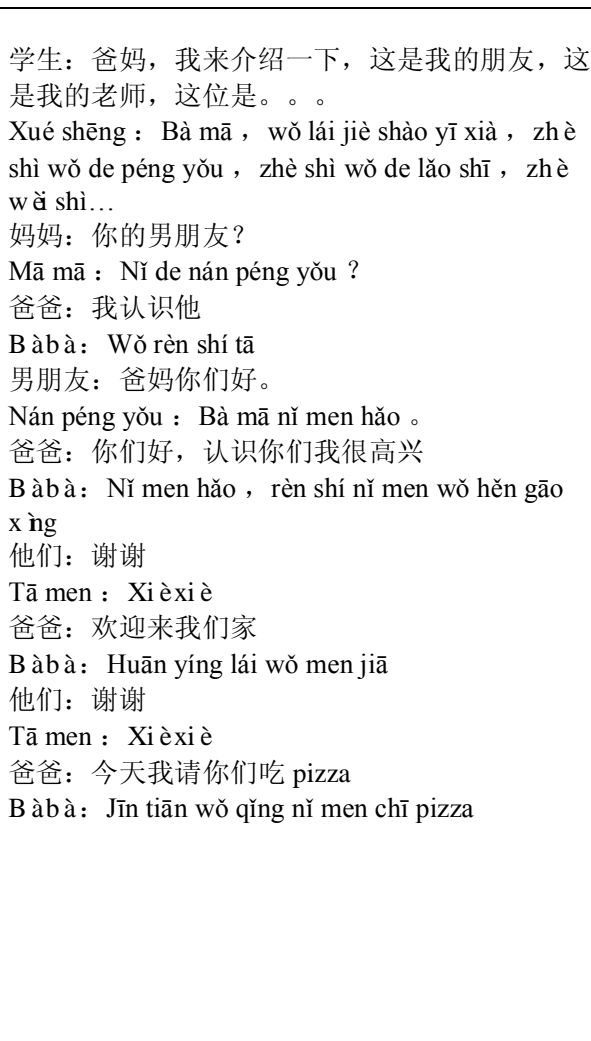 \\
\hline
\end{tabular}




\section{REFERENCES}

[1] Ashby Patricia. (2012). Phonetics in pronunciation teaching for modern foreign languages. LLAS Centre for Languages, Linguistics and Area Studies, Retrieved March 14, 2013, from http://www.llas.ac.uk/resources/gpg/408.

[2] Badin Pierre, Bailly Gérard and Boë Louis-Jean. (1998). Towards the use of a Virtual Talking Head and of Speech Mapping tools for pronunciation training, Proceedings of the ESCA Tutorial and Research Workshop on Speech Technology in Language Learning 98, 167-170.

[3] Elliott Raymond. (1994). Predicting near-native pronunciation in Spanish as a foreign language. UTA Working Papers in Linguistics 1, 51-66.

[4] Fledge, J.E. (1995). Second-language speech learning: Theory, findings and problems. In Strange, W. (Ed.), Speech perception and linguistic experience: Theoretical and methodological issues in cross-language speech research (pp. 233-272). Timonium, MD: York Press Inc.

[5] Gilbert, J. (1995). Pronunciation practices as an aid to listening comprehension. In D. J. Mendelson and J. Rubin (Eds.), $A$ guide for the teaching of Second Language Learning (pp. 97-111). San Diego: Dominic Press.

[6] Heift, T. \& Rimrott, A. (2008). Learner responses to corrective feedback for spelling errors in CALL. System, 36(2), $196-213$.

[7] Heuven Vincent, Broerse Nicole and Pacilly Jos. (2011). Perception of checked vowels by early and late Dutch/English bilinguals. Presented to M.E.H. (Bert) Schouten on the occasion of his 65th birthday Utrecht Institute of Linguistics OTS, Utrech. 103-116.

[8] Hmard, D. (2006). Design issues related to the evaluation of learner - computer interaction in a web-based environment: activities vs. tasks. Computer Assisted Language Learning, 19 (2), 261-276.

[9] Ives Susan, (2004). Instant Immersion 33 languages. PC Alamode Magazine. Retrieved May 20, 2013, from http://www.alamopc.org/pcalamode/reviews/current/R20040703.shtml.

[10] Kadenge Maxwell. (2009). African Englishes: The indigenization of English vowels by Zimbabwean native Shona speakers. The Journal of Pan African Studies, 3 (1), 156-173.

[11] Levy, M. (1997). CALL: Context and conceptualization. Oxford: Oxford University Press.

[12] Linge Olle. (2011). Teaching the third tone in standard Chinese tone representation in textbooks and its consequences for students. Unpublished Master's Thesis, Lund University, Sweden.

[13] Liu Si-yun and Samuel Arthur. (2004). Perception of Mandarin lexical tones when F0 information is neutralized. Language and Speech, 47(2), 109-38.

[14] Lund Karen. (2003). Age and accent. Sprogforum nummer 26, 9-17.

[15] Major, R.C. (1987). Foreign accent: Recent research and theory. International Review of Applied Linguistics, 25(3), 185-202.

[16] Nagel Donovan. (2011). Language shadowing: A superior learning method. The Mezzofanti Guild Language Learners. Retrieved August 7, 2013, from http://www.mezzoguild.com/2011/12/30/language-shadowing-a-superior-learning-method/.

[17] Nazlı Gündüz. (2005). Computer Assisted Language Learning (CALL). Journal of Language and Linguistic Studies, 1 (2), 193-214.

[18] Nooteboom, S. (1983). Is speech production controlled by speech perception? In Van den Broecke, J. Van Heuven \& W. Zonneveld. (Eds.), Sound structure (pp. 153-194). Dordrecht: Foris.

[19] Rajagopalan Kanavillil. (2010). The English language, Globalization and Latin America: Possible lessons from the 'Outer Circle'. In Saxena Mukul and Omoniyi Tope (Eds.), Contending with globalization in World Englishes (pp. 175-195). Bristol, UK: Multilingual Matters.

[20] Rochet, B. L. (1995). Perception and production of L2 speech sounds by adults. In Strange,W. (Ed.), Speech perception and linguistic experience: Theoretical and methodological issues in cross-language speech research (pp. 379-410). Timonium, MD: York Press Inc.

[21] Semke Harriet. (1984). Effects of the red pen. Foreign Language Annals, 17(3), 195-202.

[22] Sheerin Susan. (1987). Listening comprehension: Teaching or testing? ELT Journal. Oxford University Press, 41(2), 126-131.

[23] Tench, P. (1981). Pronunciation Skills. London and Basingstoke: Macmillan.

[24] Thompson Billie. (1993). Listening disabilities: The plight of many. In A. Wolvin \& C. Coakley (Eds.), Perspectives on listening (pp. 124-163). Norwood, NJ: Ablex.

[25] Wagner Adrian. (2012). Second language phonology and perceptual assimilation of English sounds by Japanese learners of English. Retrieved April 1, 2013, from http://www.keiwa-c.ac.jp/kenkyu/kiyo /doc/kiyo21-2.pdf.

[26] Wong, R. (1987). Teaching pronunciation: Focus on English rhythm and intonation. Englewood Cliffs, NJ: Prentice Hall Regents.

[27] Zhang Fachun and Yin Pengpeng. (2009). A Study of pronunciation problems of English learners in China. Journal of Asian Social Science, 5(6). 141-146.

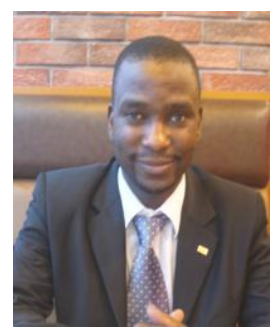

Herbert Mushangwe, Male, born in Zimbabwe in1981 studied Chinese language at Tianjin Normal University and passed Chinese Proficiency Test level 6 in 2009, also obtained his Masters in Teaching Chinese as a Second Language at the same Institution in 2011.

He is a LECTURER in the Confucius Institute at the University of Zimbabwe; the first Zimbabwean to teach Chinese language at University level. Currently, he is at Hebei University studying towards PHD in Chinese Linguistics mainly focusing on Teaching Chinese as a Second language, at the same time he is working on the Shona-Chinese handbook project which is being funded by HANBAN through the Confucius Institute at the University of Zimbabwe.

Mr Mushangwe's Shona-Chinese comparative research articles which were written and presented in Chinese at the Tianjin Linguists Association End of year conferences held in 2009, 2010 and 2013 won special awards under the foreign students' research articles category. 